\title{
Minimally Invasive Mini-orbitozygomatic Approach for Clipping an Anterior Communicating Artery Aneurysm: Virtual Reality Surgical Planning
}

\section{Abordagem mini-orbitozigomático minimamente invasiva para clipagem de um aneurisma da artéria comunicante anterior: planejamento cirúrgico de realidade virtual}

\author{
Nicolás González Romo ${ }^{10}$ Franco Ravera Zunino ${ }^{10}$ \\ ${ }^{1}$ Department of Neurosurgery, Hospital Regional Rancagua, \\ Rancagua, Chile \\ Address for correspondence Nicolás González Romo, MD, \\ Department of Neurosurgery, Hospital Regional Rancagua, Rancagua, \\ Chile (e-mail: ngonzalezr@ug.uchile.cl).
}

Arq Bras Neurocir 2021;40(3):e288-e293.

\begin{abstract}
Keywords

- virtual reality

- intracranial aneurysm

- microsurgery

- skull base

Resumo

Palavras-chave

- realidade virtual

- aneurisma intracraniano

- microcirurgia

- base do crânio

Virtual reality (VR) has increasingly been implemented in neurosurgical practice. A patient with an unruptured anterior communicating artery (AcoA) aneurysm was referred to our institution. Imaging data from computed tomography angiography (CTA) was used to create a patient specific 3D model of vascular and skull base anatomy, and then processed to a VR compatible environment. Minimally invasive approaches (mini-pterional, supraorbital and mini-orbitozygomatic) were simulated and assessed for adequate vascular exposure in VR. Using an eyebrow approach, a miniorbitozygomatic approach was performed, with clip exclusion of the aneurysm from the circulation. The step-by-step process of VR planning is outlined, and the advantages and disadvantages for the neurosurgeon of this technology are reviewed.

A realidade virtual (RV) é uma ferramenta cada vez mais utilizada na prática neurocirúrgica. Apresentamos um caso de aneurisma da artéria comunicante anterior (AcoA) sem rompimento com planejamento cirúrgico por RV. Os dados da angiografia por tomografia computadorizada (ATC) DICOM foram usados para a criação de um modelo 3D da anatomia vascular e da base do crânio do paciente, seguido de análise em um ambiente compatível com RV. Abordagens minimamente invasivas (minipterional, supraorbital e mini-orbitozigomática) foram simuladas e avaliadas quanto à exposição vascular adequada na RV. Utilizando uma abordagem pela sobrancelha, foi realizada uma abordagem mini-orbitozigomática, com exclusão do aneurisma da circulação. O processo passo a passo do planejamento da RV foi descrito e foram revisadas as vantagens e desvantagens desta tecnologia.
\end{abstract}

received

April 11, 2020

accepted

August 24, 2020

published online

November 26, 2020
DOI https://doi.org/ 10.1055/s-0040-1719004 ISSN $0103-5355$.

\footnotetext{
(c) 2020. Sociedade Brasileira de Neurocirurgia. All rights reserved. This is an open access article published by Thieme under the terms of the Creative Commons Attribution-NonDerivative-NonCommercial-License, permitting copying and reproduction so long as the original work is given appropriate credit. Contents may not be used for commercial purposes, or adapted, remixed, transformed or built upon. (https://creativecommons.org/ licenses/by-nc-nd/4.0/)

Thieme Revinter Publicações Ltda., Rua do Matoso 170, Rio de Janeiro, RJ, CEP 20270-135, Brazil
} 


\section{Introduction}

Surgical planning is a critical step in cerebrovascular surgery. Appropriate selection of surgical approaches, angle of attack, and potential clip configuration may be optimized by meticulous assessment of the patient angiographic images.

Virtual reality (VR) has increasingly been adopted as a technology with potential benefits for neurosurgery, allowing a reduced learning curve of complex procedures, improved visuospatial skills, and understanding of complex anatomical relationships. ${ }^{1,2}$

Digital imaging and communications in medicine (DICOM) data from computed tomography angiography (CTA) can be used to create accurate and individualized 3D models of the patient skull base and vascular anatomy. These 3D models can later be transferred to a virtual reality environment, obtaining in this process "stereopsis" 3 , which is a sense of depth from binocular vision that translates to optimized visuospatial interpretation.

Using VR, the neurosurgeon can have a more accurate, preoperative interaction with the patient's unique anatomy. In the VR environment, different surgical approaches can be simulated, and surgical strategy rehearsed.

Our goal is to outline our step-by-step process of VR surgical planning, including DICOM data processing and creation of VR models of different surgical approaches, applied successfully in the case of a patient with an unruptured anterior communicating artery (AcoA) aneurysm treated at our center, and briefly point the advantages and disadvantages of this technology.

\section{Case}

A 64-year-old female patient with medical history of arterial hypertension was admitted to our center because of headache of acute onset and was diagnosed an unruptured saccular AcoA aneurysm. The patient was neurologically intact. On CTA, the dimensions of the aneurysm were 3$\mathrm{mm}$ neck and 5-mm diameter, with an anteroinferior projection, and counter clockwise rotation of the A2 fork. This case was considered favorable for a minimally invasive approach.

\section{VR Planning}

DICOM CTA (1.0-mm thickness volumetric acquisition) was processed using the open-source DICOM software Horos version 3.3.6 (Nimble LLC, Purview in Annapolis, MD, USA). Using "grow segmentation tool," two different regions of interest (ROIs) of the polygon of Willis and of the skull bone were created. Next, in the 3D volume rendering mode, with the "scissor tool" 3 surgical approaches suitable for the case were simulated (mini-pterional, supraorbital and mini-orbitozygomatic). In the 3D surface rendering mode, red color labeling was assigned to the arterial ROI, and white color to the bone ROI. The 3D model was converted and exported to a VR compatible file.

Using Sketchfab (http://www.sketchfab.com) free online VR editor, the file was uploaded, and the texture was processed.
Using a VR headset (Zeiss $\mathrm{Vr}$ Oneplus headset), the resulting models were assessed using the first-person VR mode.

\section{Results}

A VR simulation of minimally invasive cranial approaches was performed from the side of A1 dominance (left side).

\section{Mini-pterional Approach (https:||skfb.ly/6QsxC)}

A frontotemporal curvilinear skin incision behind the line of hair implantation, is followed by interfascial dissection of the temporalis muscle. A subfascial or myocutaneous dissection can be performed as well. A fronto-temporo-sphenoidal craniotomy, as described by Figueiredo et al., ${ }^{4}$, includes bone removal from the keyhole region, posterior to the frontozygomatic suture, lateral to the superior temporal line and anterior to the stephanion (-Fig. 1.A, B).

\section{Supraorbital Approach (https:||skfb.ly|6Qt6w)}

After an eyebrow incision, following the description of Perneckzy, ${ }^{5}$ frontal bone removal begins in the keyhole region and continues parallel to the supraorbital rim curving backward lateral to the supraorbital notch, avoiding entering the frontal sinus. The orbital roof is flattened with a cutting or diamond burr (-Fig. 1C, D).

\section{Mini-orbitozygomatic Approach (https:||skfb.ly| 6Qtos)}

This approach can be performed both from an eyebrow incision, or after a frontotemporal curvilinear incision behind the hairline insertion. Interfascial of subfacial dissection of the temporalis muscle is required. A proper MacCarty keyhole is followed by removal of a $3 \times 3-\mathrm{cm}$ bone flap that includes frontal bone, frontal process of the zygomatic bone, part of the orbital roof, and the supraorbital rim. ${ }^{6}$ (-Fig. 1 E, F)

\section{Neurovascular Anatomy, Approach Selection, and Dissection Strategy}

The left A1 was dominant and had a trajectory directed first posteriorly and then curved back anteriorly into the AcoA complex. The A2 fork was rotated counterclockwise to the left side. The contralateral A1 joined the AcoA complex posteriorly. Because of the lack of contrast enhancement, the perforators and recurrent artery of Heubner were not represented in the VR model.

The aneurysm originated form the AcoA and projected inferiorly into the chiasmatic groove of the sphenoid (-Fig. 2). Optimal exposure of the aneurysm neck was obtained with a view axis almost perpendicular to the orbital roof. For this reason, a mini-orbitozygomatic approach was selected because it offered a better trajectory, perpendicular to the aneurysm neck, creating a corridor unobstructed by the orbital roof, and also offered an increased upward view angle toward the A2. Dissection strategy included exposure of optic-carotid and interoptic space. Because of a curved and deep trajectory of the ipsilateral A1, an arterial exposure 

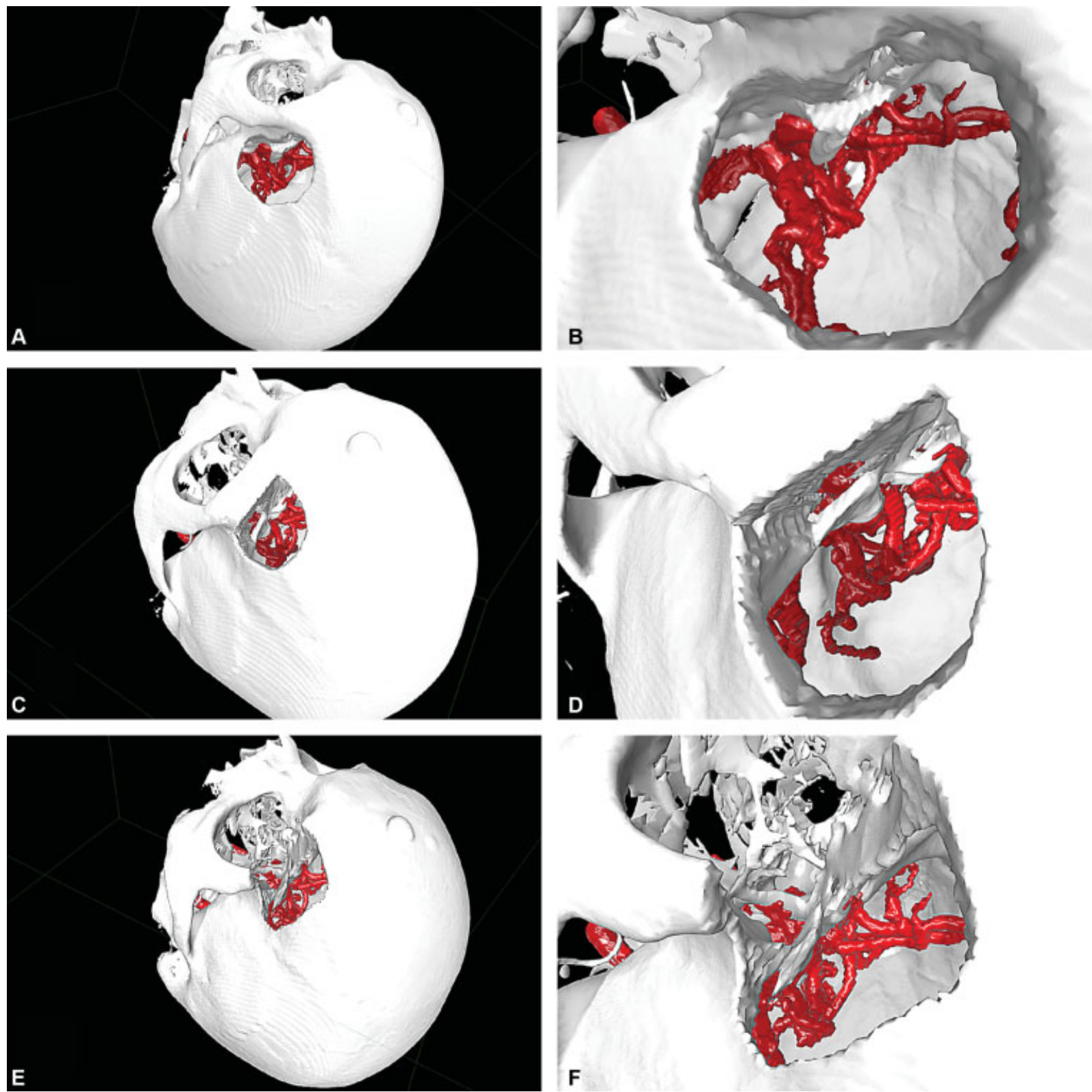

Fig. 1 Virtual reality simulation of surgical approaches. (A, B) Mini-pterional craniotomy. (C) (D) Supraorbital craniotomy. (D, E) Miniorbitozygomatic osteotomy.

proximal to the AcoA complex was planned. Exposure of bilateral A2's required inter-hemispheric fissure dissection. Clipping with a straight clip configuration perpendicular to the aneurysm neck was considered an optimal exclusion strategy.

\section{Surgical Technique}

A left-sided mini-orbitozygomatic approach was performed. Under general anesthesia, the patient was positioned in a Mayfield head clamp. The head was extended and rotated $\sim$ 30 degrees to the right side. Following an eyebrow incision laterally to the supraorbital notch, a fascial plane between the orbicularis oculi and the frontalis and temporalis muscles was identified. The supraorbital rim was exposed, and the supraorbital nerve was protected medially. Using a high-speed drill, a MacCarty keyhole was performed, exposing the periorbita and frontal dura. The periorbita was carefully separated from the orbital roof with a Penfield dissector. A one piece mini-orbitozygomatic bone flap was created with a craniotome, and the orbital roof was fractured with a chisel. The dura was opened in a curvilinear fashion and retracted with sutures (-Fig. 3 A). Without rigid retraction, the frontal lobe was gently mobilized posteriorly, exposing the optic-carotid cistern. Opening these cisterns allowed cerebrospinal fluid (CSF) release and brain relaxation. The supraclinoid carotid artery and optic nerve were identified (-Fig. 3 B). Further dissection revealed the aneurysm in the interoptic space projecting inferiorly into the chiasmatic groove ( - Fig. $3 \mathbf{C}$ ). The dominant ipsilateral A1 was exposed in the posterior aspect of the AcoA, and both $A 2 s$ where identified by dissection of the 

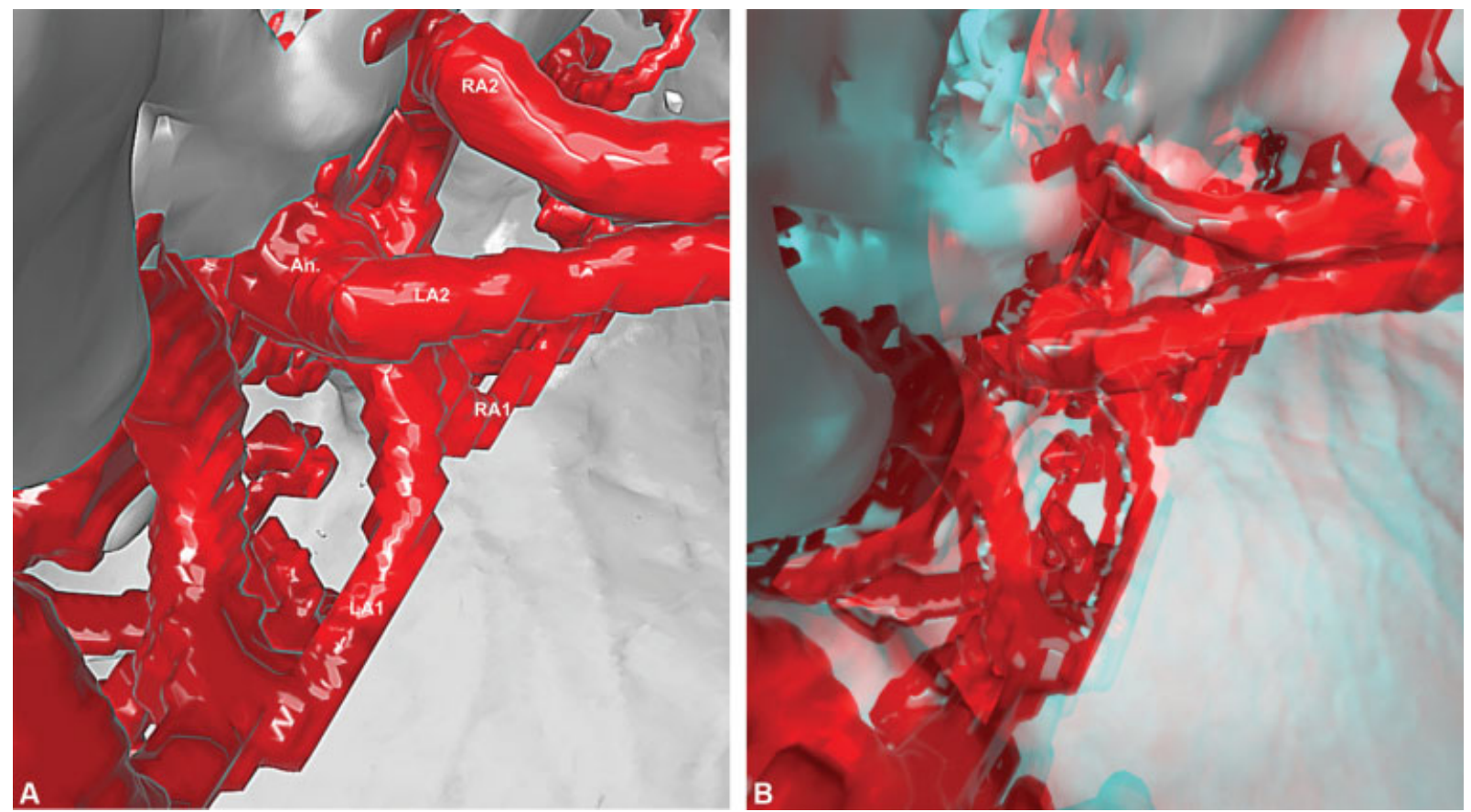

Fig. 2 Virtual reality model of vascular anatomy. (A) ICA: Internal carotid artery. LA1: left A1, RA1: right A1, AcoA: Anterior communicating artery, LA2: left A2, RA2: right A2, An: Aneurysm (B) Red/cyan anaglyph.

interhemispheric fissure, without the need of gyrus rectus resection. The ipsilateral recurrent artery was exposed at the A1-A2 junction. Two straight 7- and 9-mm Yasargil clips (Aesculap AG \& Co., Tuttlingen, Germany) were used to exclude the aneurysm from the circulation (-Fig. 3 C). Indocyanine green (ICG) videoangiography confirmed aneurysm exclusion and patency of relevant vessels and perforators. The patient had a favorable postoperative course, without complications, and was discharged neurologically intact.

\section{Discussion}

Virtual reality is a technology that has increasingly been adopted in neurosurgery. Reports that related the use of VR in neurosurgery correspond to one of the following categories: education and resident training, morphological research, surgical planning, and use as an intraoperative surgical adjunct. ${ }^{7-15}$

In our study, we focused on the use of VR as a planning tool for cerebrovascular surgery. An eyebrow mini-orbitozygomatic approach was selected to treat an unruptured AcoA aneurysm after VR simulation, with favorable exposure and clinical outcome. This approach offered a perpendicular view to the neck of the aneurysm, compared with a more parallel axis view of the mini-pterional approach, and an increased upward view angle toward the A2 (by removal of the orbital rim and roof) compared with the supraorbital approach. These were subjective observations made in the VR simulation, and objective measurements would have made our study more robust, but our goal was to describe the process of VR simulation used and not to do a morphometric VR study comparing surgical approaches.

Virtual reality is a readily available technology, requiring a low-cost investment of a smartphone VR headset to be used. Stand-alone equipment exists that offers better image quality and interaction in the VR environment but at a higher cost. A computer station with a good graphics processor is also desirable.

In the VR environment, "stereopsis"3, the sense of depth obtained from binocular vision, gives the surgeon the opportunity to asses complex spatial relationships of vascular structures before surgery and to establish a surgical plan, including patient positioning, surgical approach, vascular exposure, and aneurysm neck dissection strategy . In our opinion, the most important benefit of VR planning is observed during surgery, at which point a "déjà vu" feeling develops when exposing the relevant vascular anatomy, and the path to the aneurysm neck, as microsurgical dissection continues, is crystal clear from the beginning.

Disadvantages from our VR planning procedure include extra time required to process de DICOM images and conversion into VR files. Advanced knowledge of ROI creation and DICOM software use is required.

Soft-tissue layers, such as skin and muscle, cannot be visualized in VR. As a part of the simulation strategy, however, we took into consideration surgical steps related to soft-tissue dissection, such as skin incision and temporalis muscle dissection among others, to create a framework that is to be reproduced in surgery, and allowed us to make the decision about the best approach for the case. 

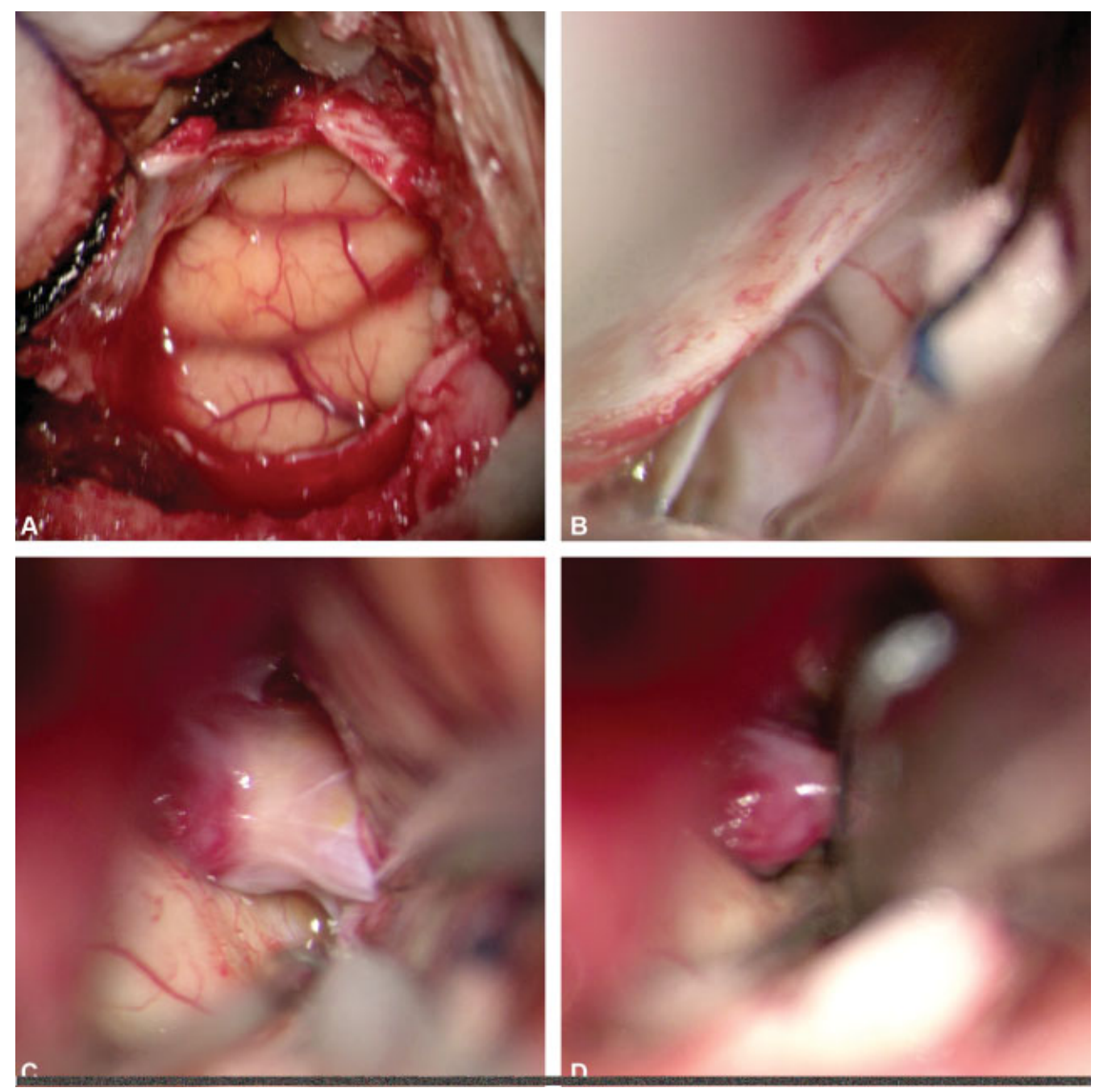

Fig. 3 Surgical Technique. (A) Dural opening. (B) Exposure of ipsilateral internal carotid artery and optic nerve. (C) Aneurysm dissection and neck exposure. (D) Clipping with straight clip.

The resulting VR model offers a gross representation of the vascular arterial anatomy and is a product of the ROI created from the vessels with contrast enhancement in CTA, so there may be artifacts, like venous vessels colored as arteries because of similar pixel values. Careful interpretation of the VR model is required. Perforators, due to lack of contrast enhancement, are usually not possible to observe in the VR model.

Overall, we believe that the advantages of this technology are superior to the disadvantages. Further studies with this technology are required to measure clinical benefit in terms of neurological outcomes

\section{Conclusion}

Virtual reality is a valuable tool for planning cerebrovascular surgery, optimizing patient positioning, surgical approach selection, dissection strategy, and clip selection.

\section{Conflict of Interests}

The authors have no conflict of interests to declare.

\section{References}

1 Bernardo A. Virtual Reality and Simulation in Neurosurgical Training. World Neurosurg 2017;106:1015-1029

2 Bernardo A. Establishment of Next-Generation Neurosurgery Research and Training Laboratory with Integrated Human Performance Monitoring. World Neurosurg 2017;106:991-1000

3 Rubio RR, Bonaventura RD, Kournoutas I, et al. Stereoscopy in Surgical Neuroanatomy: Past, Present, and Future. Oper Neurosurg (Hagerstown) 2020;18(02):105-117

4 Figueiredo EG, Deshmukh P, Nakaji P, et al. The minipterional craniotomy: technical description and anatomic assessment. Neurosurgery 2007;61(05, Suppl 2):256-264, discussion 264-265

5 Fischer G, Stadie A, Reisch R, et al. The keyhole concept in aneurysm surgery: results of the past 20 years. Neurosurgery 2011;68(01, Suppl Operative )45-51, discussion 51

6 Yagmurlu K, Safavi-Abbasi S, Belykh E, et al. Quantitative anatomical analysis and clinical experience with mini-pterional and mini-orbitozygomatic approaches for intracranial aneurysm surgery. J Neurosurg 2017;127(03):646-659

7 de Faria JW, Teixeira MJ, de Moura Sousa Júnior L, Otoch JP, Figueiredo EG. Virtual and stereoscopic anatomy: when virtual reality meets medical education. J Neurosurg 2016;125(05): $1105-1111$ 
8 Bernard F, Gallet C, Fournier HD, Laccoureye L, Roche PH, Troude L. Toward the development of 3-dimensional virtual reality video tutorials in the French neurosurgical residency program. Example of the combined petrosal approach in the French College of Neurosurgery. Neurochirurgie 2019;65(04):152-157

9 Shao X, Yuan Q, Qian D, et al. Virtual reality technology for teaching neurosurgery of skull base tumor. BMC Med Educ 2020;20(01):3

10 Alaraj A, Luciano CJ, Bailey DP, et al. Virtual reality cerebral aneurysm clipping simulation with real-time haptic feedback. Neurosurgery 2015;11(Suppl 2):52-58

11 Bairamian D, Liu S, Eftekhar B. Virtual Reality Angiogram vs 3Dimensional Printed Angiogram as an Educational tool-A Comparative Study. Neurosurgery 2019;85(02):E343-E349
12 Raabe C, Fichtner J, Beck J, Gralla J, Raabe A. Revisiting the rules for freehand ventriculostomy: a virtual reality analysis. J Neurosurg 2018;128(04):1250-1257

13 Peh S, Chatterjea A, Pfarr J, et al. Accuracy of augmented reality surgical navigation for minimally invasive pedicle screw insertion in the thoracic and lumbar spine with a new tracking device. Spine J 2020;20(04):629-637

14 Tai AX, Sack KD, Herur-Raman A, Jean WC. The Benefits of Limited Orbitotomy on the Supraorbital Approach: An Anatomic and Morphometric Study in Virtual Reality. Oper Neurosurg (Hagerstown) 2020;18(05):542-550

15 Morone PJ, Shah KJ, Hendricks BK, Cohen-Gadol AA. Virtual, 3Dimensional Temporal Bone Model and Its Educational Value for Neurosurgical Trainees. World Neurosurg 2019;122:e1412-e1415 